\title{
Erken yükleme konsepti ile oluşturulan mandibular hibrit protez hastasında ortaya çıkan fonksiyonel konuşma bozukluğunun çözümü: Alternatif bir yaklaşım
}

\author{
Serdar Kılıç ${ }^{1}$, Nuray Yılmaz Alııntaş ${ }^{2}$, Subutay Han Altıntaş ${ }^{3}$
}

Selcuk Dent J, 2016; 3: 128-134

Başvuru Tarihi: 27 Nisan 2016 Yayına Kabul Tarihi: 28 Nisan 2016

\begin{abstract}
ÖZ
Erken yükleme konsepti ile oluşturulan mandibular hibrit protez hastasında ortaya çıkan fonksiyonel konuşma bozukluğunun çözümü: Alternatif bir yaklaşım
\end{abstract}

Klasik iki-aşamalı dental implant konsepti, geçtiğimiz yıllardaki bir çok çalışmada olumlu sonuçlar ortaya koysa da, uzun osseointegrasyon süresi, randevu sayısının fazla olması, geçici bir tam protez yapımı ve bu protezlerin bir çok kez astarlama gerekliliği gibi bazı dezavantajları beraberinde getirmektedir. Dental implantların materyal, dizayn ve yüzey isslemlerinde ortaya çıkan son dönemdeki yenilikler ve gelişmeler, klinik diş hekimliği için önemli bir konsept olan erken yükleme protokolünün ortaya çıkmasına ön ayak olmuştur. Erken yükleme protokolünü temel alan birçok yöntemde ortaya çıkan en önemli dezavantaj içerdikleri ölçü alma işlemleri sebebiyle operasyon bölgesinin zarar görebilmesidir. Son dönemde bu problemi ortadan kaldırmak amacıyla ölçü alma prosedürlerini içermeyen Ohio State University (OSU) protokolü geliştirilmiştir. Ancak bu protokolde de, postperatif iyileşme gerçekleşmeden protetik işlemlerin tamamlanması sebebiyle hastalarda konuşma problemleri baş gösterebilmektedir. Bu çalışmada, OSU protokolü temel alınarak erken yükleme konsepti ile yapılan implant destekli bir mandibular hibrit protezde, postoperatif iyileşme sonrasında meydana gelen fonksiyonel konuşma problemini ortadan kaldıran alternatif bir yöntemin sunumu ve bu yöntem sonrasında ortaya çıkan neticenin gösterilmesi amaçlanmaktadır.

62 yaşındaki erkek hasta, implant operasyonu sonrası OSU protokolü ile oluşturulan alt hibrit protezinden kaynaklanan fonksiyonel konuşma problemi şikayeti ile kliniğimize başvurdu. Hastada, postoperatif iyileşme sonrasında protez ile mukoza arasındaki mesafe artışını telafi etmek amacıyla akrilik rezin kullanılarak alternatif bir yaklaşım uygulanmaya karar verildi.

$\mathrm{Bu}$ yaklaşım sayesinde hibrit protez ile mukoza arasındaki mesafe, hijyeni ve fonasyonu etkilemeyecek şekilde azaltılmış oldu.

$\mathrm{Bu}$ olgu sunumunda ortaya konan alternatif tekniğin, OSU protokolü baz alınarak erken yükleme konsepti ile ağıza yerleştirilen dentalimplant destekli hibrit protezlerde ortaya çıkabilecek fonasyon problemlerinin çözümünde geçerli bir yöntem olabileceği gösterilmektedir. Bu yöntemle hastanın karşı karşıya kaldığı psikososyal dezavantaj konforlu ve kısa bir sürede kolaylıkla ortadan kaldırımıştır.

\section{ANAHTAR KELIMELER}

Dental Hibrit Protezler, Erken Yükleme Konsepti, Fonksiyonel Konuşma Bozukluğu, OSU Protokolü

\section{ABSTRACT \\ The rehabilitation of a patient who received oral bisphosphonate treatment with dental implant supported prosthesis: A case report}

Although classic two-step concept for dental implants has presented encouraging outcomes, treatment protocol requires a lengthy period for osseointegration. The other disadvantage of conventional implant therapy is the need for several appointments and temporary complete dentures with multiple relines. Along with continuous improvements in implant materials, designs and surface treatment techniques, immediate/early loading protocol has become one of the most remarkable achievements in clinical dentistry. Immediate loading procedures may increase the possibility of damage to the surgical site during the impression procedures. The Ohio State University (OSU) protocol has been developed to compensate for previous early loading techniques' inadequacy. However, this protocol may cause phonation difficulty to the patient due to postoperative healing. The aim of this study was to describe an alternative technique to eliminate the cause of the functional dysphonia in a patient with early load mandibular hybrid prosthesis via the OSU protocol and to evaluate the outcomes of this technique.

A 62-years-old male patient reported to our department with a complaint of functional dysphonia after the prosthetic rehabilitation with implant-retained mandibular hybrid prosthesis via OSU protocol. Acrylic resin applied to the metal framework of mandibular hybrid prosthesis decrease the distance between hybrid prosthesis and mucosa. Result: This alternative technique has led to eliminate the cause of dysphonia in a short period of time and resulted in patient satisfaction in terms of hygiene and phonation.

So it may be an appropriate technique for functional dysphonia patient with early load mandibular hybrid prosthesis and may further psychosocially motivate patients in the social environment.

\section{KEYWORDS}

Dental Hybrid Prosthesis, Early Loading Concept, Functional Dysphonia, OSU Protocol

\footnotetext{
${ }^{1}$ Kocaeli Üniversitesi Diş Hekimliği Fakültesi Protetik Diş Tedavisi Anabilim Dalı, Kocaeli

${ }^{2}$ Karadeniz Teknik Üniversitesi Diş Hekimliği Fakültesi Ağız Diş ve Çene Cerrahisi Anabilim Dalı, Trabzon

${ }^{3}$ Karadeniz Teknik Üniversitesi Diş Hekimliği Fakültesi Protetik Diş Tedavisi Anabilim Dalı, Trabzon
} 
Illk kez Branemark tarafından oluşturulan klasik iki aşamalı dental implant protokolü, geçtiğimiz 30 yıl boyunca birçok araştırmacı tarafından incelenmiş, rehabilitasyonun prognozu çok sayıda çalışma aracılığıyla iyi bir şekilde belgelenmiştir (Stephan ve ark. 2007, Friberg ve ark. 2005). Konsept genel olarak, fonksiyonel bir yükleme yapılmadan önce 3 ile 6 ay arasında değişen iyileşme süresine sahip iki aşamalı cerrahi prosedürü içermektedir. Hastaların, bu protokolde cerrahi ve protetik prosedürler boyunca 46 aylık süre içerisinde ortalama 10 defa kliniğe gelmesi gerekebilmektedir (Turkyilmaz ve ark. 2009, Friberg ve ark. 2000). Uzun osseointegrasyon süresi ve randevu sayısının fazla olmasının yanı sıra dişsiz hastalarda geçici bir tam protez yapımı ve bir çok kez astarlama gerekliliği bu protokolün diğer dezavantajları arasında sayılabilir (Turkyilmaz ve ark. 2009)

\section{Erken yükleme protokolü}

Hastaların daha kısa sürelerde protetik işlemi sonlandırma istekleri, dental implantların materyal, dizayn ve yüzey işlemlerinde ortaya çıkan son dönemdeki yenilikler ve gelişmeler erken yükleme protokolünün ortaya çıkmasına imkan sağlamıştır. Bu sayede, cerrahi, protetik ve dental laboratuvar işlemleri modifiye edilerek hastanın estetik, fonksiyon ve konforu daha kısa bir sürede telafi edilmiş olur. Ayrıca bu protokolde geçici bir proteze ve ikinci bir cerrahi müdahaleye gerek duyulmamaktadır (Cannizzaro ve ark. 2007, Turkyilmaz ve ark. 2006, Peñarrocha-Oltra ve ark. 2013). Yapılan çalışmalarda özellikle kemiğin yoğun ve nispeten daha kaliteli olduğu anterior mandibula bölgesinde erken yükleme protokolünün klasik iki aşamalı dental implant protokolü ile kıyaslanabilir şekilde başarılı sonuçlar ortaya koyduğu gösterilmiş, uygun şartların sağlandığı hastalarda geçerli bir yöntem olabileceğinin altı çizilmiştir (Desmet ve ark. 2007, Engquist ve ark. 2005, Henry ve Rosenberg 1994, Tarnow ve ark. 1997, Cooper ve ark. 2007).

\section{Ohio State University (OSU) protokolü}

OSU protokolü ilk kez 2004 yılında, Ohio State Üniversitesi'nde bir grup araştırmacı tarafından alternatif bir erken yükleme yöntemi olarak geliştirilmiştir. Dental implant operasyonundan hemen sonraki ilk günlerde ağıza yerleştirilebilen, kişiye özel, vidalanabilir bir hibrit protez yapımını içeren bu protokolün temelini dökülebilir akrilik rezin altyapı (patern) oluşturmaktadır. Operasyon sonrasında, implantlara uyumlu olacak şekilde modifiye edilebilen rezin patern yardımıyla kişiye özel metal altyapının döküm işlemi gerçekleştirilir. Döküm öncesinde istenildiği gibi kolayca modifiye edilebilmesi nedeniyle hasta ağzına uyumlu protezler elde edilebilir. Bu protokolün en önemli avantajlarından biri de tüm implant sistemlerinde uygulanabilir olmasıdır. Her türlü anatomik varyasyona, ark formuna ve büyüklüğüne uygun hazırlanabilmesi hekime önemli ölçüde avantaj sağlamaktadır (Tames ve ark. 2004).

Erken yükleme protokolünde operasyonun ardından henüz suture edilmiş alanda irritasyon ve kanama riski oluşturabilmesi dezavantaj olarak ortaya çıkabilmektedir. OSU protokolünde ölçü alma prosedürlerinin olmaması nedeniyle bu risk biraz daha düşüktür (Turkyilmaz ve ark. 2009). Bununla birlikte postoperatif iyileşme tamamlanmadan protetik işlemlerin sonlandırılması ve ağıza yerleştirilmesi sebebiyle uzun dönemde bazı estetik ve fonksiyonel problemlerin ortaya çıkma riski bu konseptin diğer dezavantajıdır. Erken yükleme protokollerinde, iyileşmeye bağlı olarak yumuşak dokularda meydana gelen çekilmeler protetik restorasyonun estetiğine etki edebilmekte, hastanın fonasyonunda bozukluklara neden olabilmektedir.

$\mathrm{Bu}$ makalede, OSU protokolü temel alınarak erken yükleme konsepti ile yapılan bir implant-destekli hibrit protezde, postoperatif iyileşme sonrasında meydana gelen fonasyon problemini ortadan kaldıran alternatif bir yöntemin sunumu amaçlanmaktadır.

\section{OLGU SUNUMU}

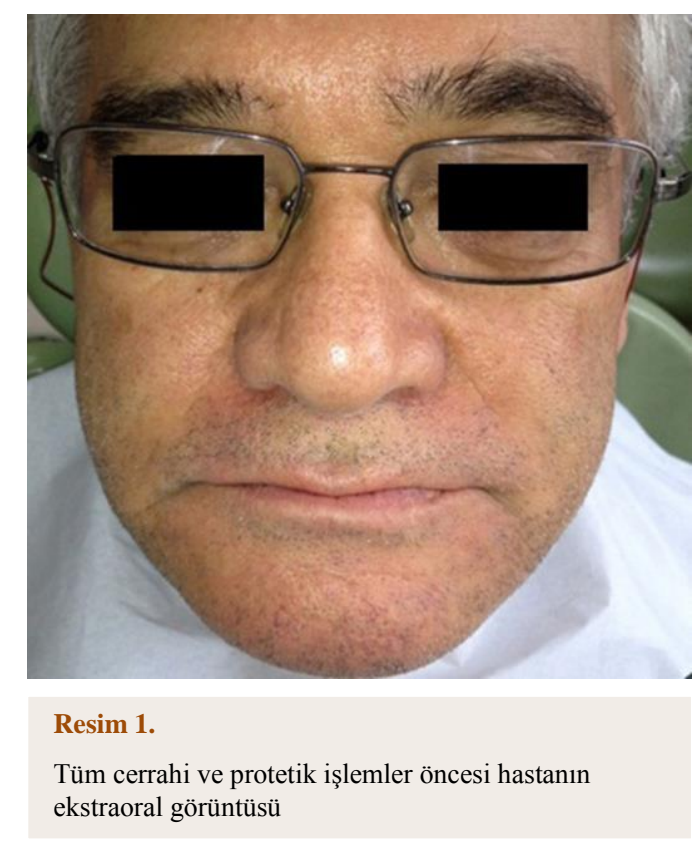

62 yaşında dişsiz erkek hasta, estetik ve fonksiyonel şikâyetleri sebebiyle Karadeniz Teknik Üniversitesi Diş Hekimliği Fakültesi Protetik Diş Tedavisi kliniğine başvurmuştur (Resim 1). Anamnezinde herhangi bir sistemik rahatsızlığı bulunmayan hastanın intraoral ve radyografik muayenesi sonrası, her iki çenesindeki alveol kemiğinde şiddetli rezorbsiyon tespit edildi. Var 
olan dikey boyut kaybını telafi etmek, kaybolan estetik ve fonksiyonun sorunsuz şekilde idame edilmesini sağlamak amacıyla hastaya, implant destekli maksiller ve mandibular hibrit protez yapımı planlandı. Hastanın sosyoekonomik durumu da dikkate alınarak alt çenesine OSU protokolünü temel alan erken yükleme konsepti ile protetik rehabilitasyon yapılmasına karar verildi.

\section{OSU protokolü}

Radyografik muayene de hastanın anterior mandibula bölgesinde mental foramenler arasında OSU protokolüne uygun kemik kalitesinin var olduğu belirlendi. Maxillomandibular ilişkinin ve interoklüzal mesafe değerlendirildi ve planlanan tedavi için uygun olduğu belirlendi. Operasyon öncesinde alınan ölçülerle elde edilen modeller üzerinde üst çeneye geçici tam protez yapımında kullanılmak üzere akrilik kaide plağı (Meliodent; Heraeus Kulzer GmbH, Hanau, Almanya), alt çeneye ise ark şekline uygun olacak şekilde akrilik rezin patern (Pattern Resin LC, GC America Inc, $A B D$ ) oluşturuldu. Bu akrilik rezin patern üzerine açlan delikler sayesinde operasyon sırasında hem dental implant uygulamasına rehberlik oluşturuldu, hem de döküm işlemi ile daimi hibrit protezin metal altyapısının elde edilmesi sağlandı.

Bu protokolde amaç operasyon sonrasındaki ilk 4 gün içerisinde daimi protezi bitirmektir. Bu doğrultuda operasyon günü, hastaya onam formu imzalatılıktan sonra daha önce yapılan planlama ve akrilik rezin paterne uygun şekilde Karadeniz Teknik Üniversitesi Diş Hekimliği Ağız Diş ve Çene Cerrahisi ameliyathanesinde lokal anestezi altında maksillaya 6 adet, anterior mandibulada mental foramenler arasına da 5 adet dental implant (Astra Tech, Mölndal, İsveç) uygulandı ve alt çenede bulunan implantlar torklandı. Tork değerlerinin erken yükleme için primer stabilitenin olması gereken tork değerinin en az $30 \mathrm{Ncm}$ olmasına dikkat edildi. Uniabutment EV (Astra Tech, Mölndal, İsveç) abutmentlar vidalandıktan sonra cerrahi prosedür sutur işlemi ile tamamlandı. Aynı gün içerisinde hasta protez kliniğine getirildi. Uniabutment EV' ler üzerine dökülebilir plastik abutmentlar (Burnout Cylinder, Astra Tech, Mölndal, İsveç) vidalandı. Önceden hazırlanan akrilik rezin patern, bu kopingler üzerine uygun bir şekilde yine dökülebilir akrilik rezin yardımı ile sabitlendi. Bu noktada protez ile mukoza arasındaki mesafe hastanın hijyeni göz önünde bulundurarak $2 \mathrm{~mm}$ olarak belirlendi. $\mathrm{Bu}$ işlem sonrasında rezin patern ve plastik döküm kopingleri tek bir parça halinde vidaların gevşetilmesi yoluyla ağızdan uzaklaştııılı ve hasta evine gönderildi. Çıkarılan akrilik rezin patern ve kopinglere laboratuvar analogları monte edildi ve bu şekilde alçı içerisine gömülerek ağız içerisinden ölçü almaksızın model elde

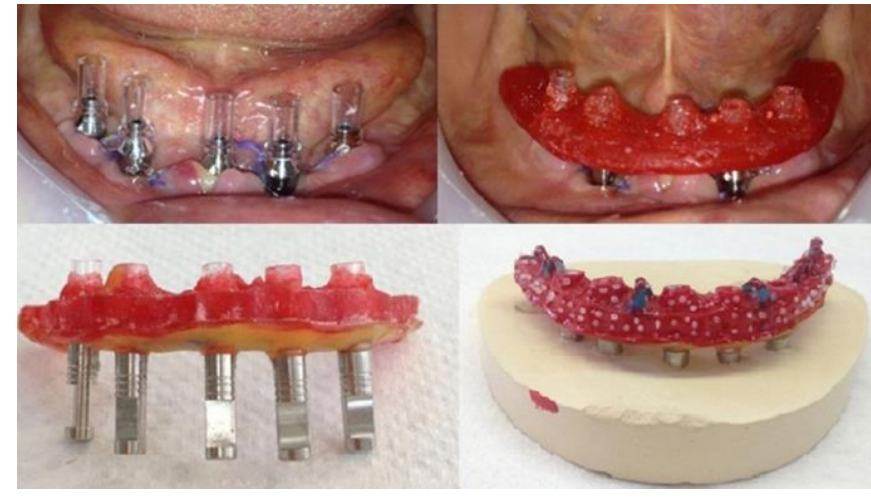

Resim 2.

Cerrahi operasyonun hemen sonrasında ağız içerisinde modifiye edilen rezin patern sayesinde ölçü almaksızın alçı model elde edildi ve döküm işlemine gönderildi

edilmiş oldu (Resim 2). Bu model üzerinde akrilik rezin paternin son düzenlemeleri yapıldıktan sonra döküm işlemleri gerçekleştirildi. Elde edilen metal altyapının pasif oturup oturmadığı model üzerinde kontrol edildi. Bir sonraki gün hasta kliniğe çağrıldı ve metal alt yapı ağız içerisinde prova edildi. Klinik ve radyografik kontrollerin sonrasında metal altyapının pasif ve tam uyumlu bir şekilde oturduğundan emin olduktan sonra, üst çenede geçici tam protez için hazırlanan kaide ve oluşturulan mum duvarlar yardımıyla hastanın dikey boyutu belirlendi. Laboratuvar ortamında akrilik yapay dişlerin dizimi gerçekleştirildi ve 3 . gün ağız içinde yapılan provalarla estetik, fonksiyon ve fonasyonun idamesi kontrol edildi. Son düzeltmeler yapıldı ve protezler bitim işlemleri için tekrar laboratuvara gönderildi. 4. gün, ISı ile polimerize olan akrilik rezin (Meliodent; Heraeus Kulzer GmbH, Hanau, Almanya) kullanılarak bitim işlemleri gerçekleştirilen ve polisaj işlemleri tamamlanan mandibular hibrit protez ve maksiller geçici tam protez ağıza yerleştirildi. Hibrit protezin abutmentlar üzerine yerleşimi ve protezler arası oklüzal ilişkiler dikkatli bir şekilde kontrol edildi. 4 . günün sonunda alt çeneye OSU protokolü ile oluşturulan daimi hibrit protez ve üst çeneye de iyileşme sürecinde kullanılacak olan geçici tam protez yerleştirilmiş oldu (Resim 3). Bilateral balanslı oklüzyon konseptine uygun şekilde oklüzal uyumlandırmalar tamamlandıktan sonra hastaya ağız hijyen eğitimi detaylı şekilde anlatıldı ve yumuşak diyet önerildi. Protetik tedavi sonrasındaki 3.gün, 2. hafta, 1 ve 3 . aylarda hasta kontrole çağrıldı. 


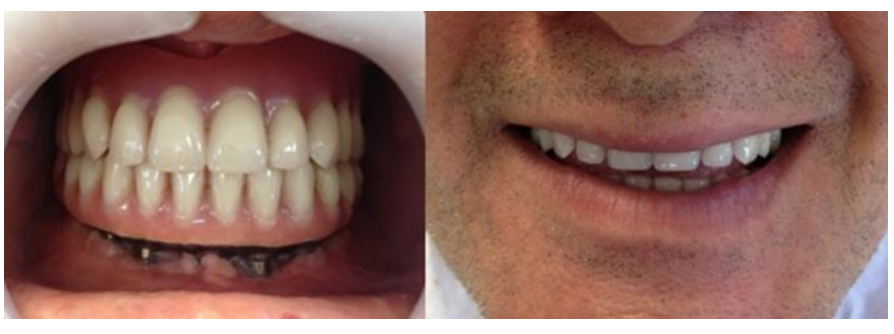

Resim 3.

OSU protokolü ile oluşturulan daimi alt çene hibrit protez ve iyileşme sürecinde kullanılacak olan üst çene geçici tam protezin görüntüsü (Operasyondan sonraki 4. günde protez bitirildiğinden alt çenede iyileşmenin henüz tamamlanmadığı görülmekte)

Dental implantların cerrahi olarak yerleştirilmesinin ardından geçen 3 aylık iyileşme süreci sonrasında, üst çeneye planlanan daimi hibrit protez yapımı için kliniğe başvuran hastanın, OSU protokolü baz alınarak yapılan alt hibrit protez ile ilgili fonasyon açısından bazı şikayetlerinin olduğu belirlendi. Yapılan ağız içi ve radyografik muayenesinde, operasyon sonrasındaki iyileşme süreci boyunca implantların çevresindeki kemik miktarında herhangi bir değişiklik olmamakla birlikte, hibrit protez ile mukoza arasındaki mesafenin düşük miktarlarda da olsa artmış olduğu ve bu durumun hastanın konuşmasına etki ettiği gözlendi (Resim 4).

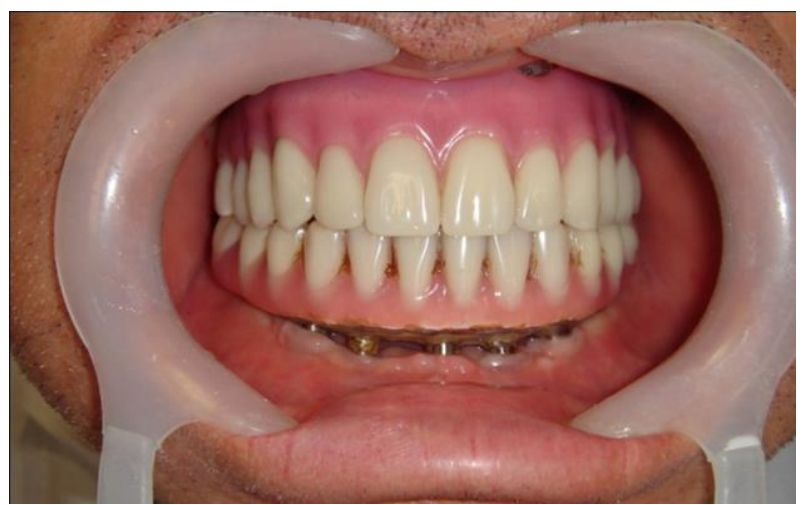

Resim 4.

Operasyondan sonraki 3 aylık iyileşme sürecinin ardından alt çene hibrit protezin ile mukoza arasındaki boşlukta artış meydana gelmiştir

\section{Alternatif yöntem}

Ortaya çıkan bu problemin çözümü için alt hibrit protezin modifiye edilmesi yoluyla mukoza ile olan aralığın azaltııması planlandı. Bu doğrultuda;

1. Öncelikle ortaya çıkan boşluğun doğru bir şekilde laboratuvar ortamına yansıtılabilmesi amacıyla, alt hibrit protez ağız içerisinde iken mukozaya bakan kısımlarına tabancalı ilave tip silikon ölçü malzemesi (Zhermack SpA, Badia Polesine, İtalya) uygulandı (Resim 5).

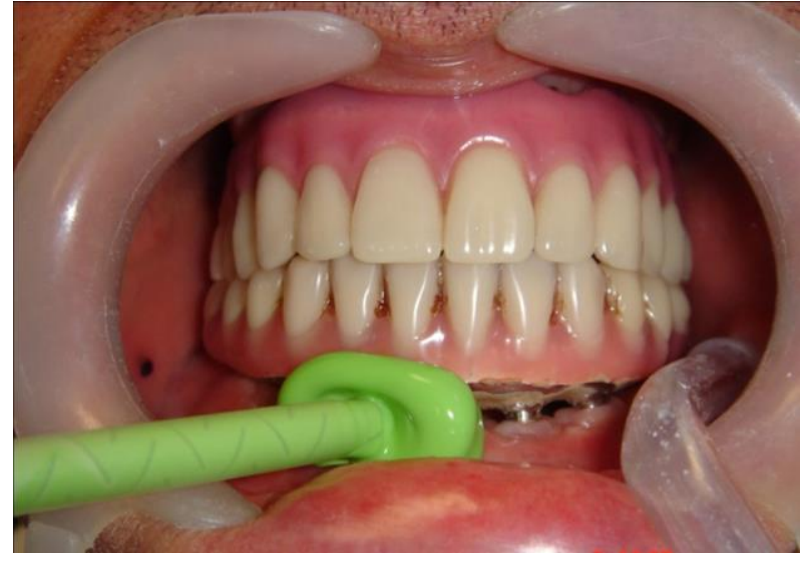

Resim 5.

Alt çene hibrit protez ağızda iken mukozaya bakan kısımlarına tabancalı ilave tip silikon ölçü malzemesinin uygulanması

2. Silikon ölçü malzemesinin polimerize olması sonrasında hibrit protez dikkatli bir şekilde ölçü malzemesiyle birlikte tek bir parça halinde vidaların gevşetilmesi yoluyla ağız içerisinden uzaklaştıııldı (Resim 6).

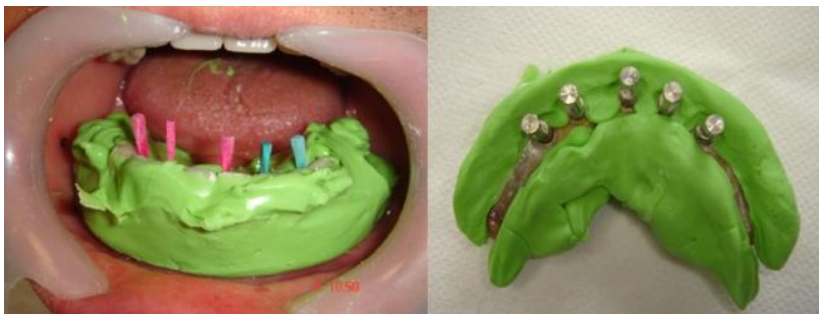

Resim 6.

Silikon ölçü malzemesinin polimerize olması sonrasında protez ölçü malzemesiyle birlikte tek bir parça halinde ağız içerisinden uzaklaştırıldı

3. Ağız dışında hibrit proteze laboratuvar analogları monte edildi ve protez dikkatli bir şekilde alçı içerisine gömüldü. Oluşturulan bu model sayesinde, ağız içerisindeki hibrit protez ile mukoza arasında var olan mesafe, laboratuvar ortamına sorunsuz ve pratik bir şekilde kişisel ölçü kaşığı yapılmadan aktarıldı.

4. Hibrit protez ile mukoza arasındaki bu boşluk metal altyapının mukozaya bakan yüzüne ısıyla polimerize olan akrilik rezin ilave edilmesi yöntemi ile $2 \mathrm{~mm}$ olacak şekilde azaltıldı. Böylece hem ağız hijyeni idame ettirildi hem de sonradan meydana gelen fonasyon problemleri ortadan kaldıııdı

5. Konvansiyonel yöntemlerle tamamlanan üst çene hibrit protez ve alternatif yöntem yardımıyla mukoza ile arasındaki mesafesi azaltılan alt çene hibrit protez bitim ve polisaj işlemleri sonraşnda ağıza pasif 
olarak yerleştirildi. Oklüzal ve radyografik kontroller sonrasında protetik tedavi sonlandırıldı

Protetik tedavi sonrasındaki 7. gün, 1., 3., 6. ve 12. aylarda hasta kontrole çağrıldı, bu kontrollerde yapılan klinik ve radyografik muayenelerde hem implantlarda hem de dental hibrit protezlerde herhangi bir problem ile karşılaşılmadı (Resim 7).

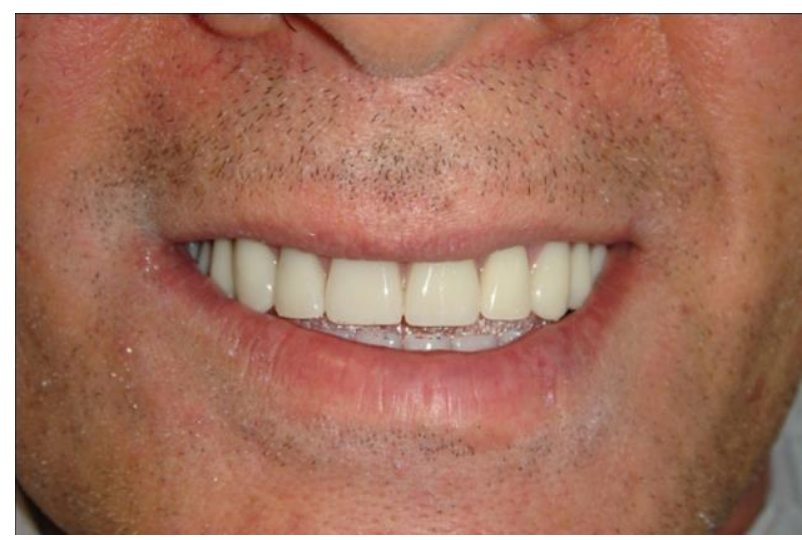

Resim 7.

İmplant-destekli maksiller ve mandibular hibrit protezlerin protetik işlemler ve uygulanan alternatif yöntem sonrası görüntüsü

\section{TARTIŞMA}

İmplant destekli sabit protezler, dişsiz çenelerin rehabilitasyonunda giderek daha da yaygın şekilde kullanılan, geçerli bir tedavi yöntemidir. Bu tip hastalarda tam protez kullanımına nazaran implant destekli sabit protez kullanımıyla daha yüksek başarı oranı elde edilmektedir. Implant destekli restorasyonlar sayesinde hastanın kaybettiği estetik ve fonksiyon kabul edilebilir seviyede geri kazandırılabilir, hastaya tutuculuk ve destek açısından kuvvetli bir protetik rehabilitasyon sağlanabilir (Malo ve ark. 2012, Jemt 2008). Dental implant destekli hibrit protezler, metal bir altyapı üzerine ISI ile polimerize olan akrilik rezin ve akrilik yapay dişlerden oluşur. Protez, implantlar ya da abutmentlar üzerine hekim tarafından vida ile sabitlenmektedir. Bu sayede kullanım sırasında retansiyon açısından sorun oluşmazken, farklı sebeplerden dolayı gerektiğinde protez hekim tarafından kolaylıkla çıkarılabilir. Yapılan çalışmalarda bu tip protezlerin, implant destekli overdenture ve konvansiyonel hareketli protezlere nazaran psikososyal açıdan daha yüksek hayat kalitesi sağladığı gösterilmiştir. Doğal dişlere yakın bir hayat kalitesi sağlaması ve kaybedilen fonksiyonu kabul edilebilir derecede geri kazandırması, hastalara önemli bir psikolojik avantaj getirmektedir (Preciado ve ark. 2013). Bununla birlikte sabit bir hibrit protezin, implant destekli hareketli overdenture protezlere nazaran daha düşük komplikasyon riskine sahip olduğu yapılan çalışmalarda gösterilmiştir (Nedir ve ark. 2006). Ayrıca dental hibrit protezlerin yapımında kullanılan akrilik rezinin, protez üzerine gelen kuvvetlerin oluşturduğu etkiyi absorbe edebilme özelliği bulunmaktadır (Gracis ve ark. 1991). Bu durum, hem distal kantilevere sahip olan bu tip protezlerin, hem de üzerine vidalandığı dental implantların başarısı için önem arz etmektedir.

Özellikle tam dişsiz hastalarda planlama yapılırken interoklüzal boşluğun ve alveolar kemik rezorbsiyon miktarının çok iyi değerlendirilmesi gerekmektedir. $\mathrm{Bu}$ iki etken,hastaya uygulanacak olan protetik tedavi seçeneğinin belirlenmesi ve prognozunun idame ettirilmesinde önemli rol oynar. Çeneler arasındaki boşluğun fazla olduğu durumlarda implant destekli sabit bir protetik restorasyon yerine dental hibrit protez yapımı tercih edilmelidir (RealOsuna ve ark. 2012). Bu vaka raporunda interoklüzal mesafenin fazla olması ve her iki çenedeki özelliklede posterior bölgedeki alveol kret rezorbsiyonları göz önünde bulundurularak hastaya uygulanacak protetik tedavi seçeneği olarak implant-destekli maksiller ve mandibular hibrit protez tercih edildi.

Dental implant uygulamalarının orijinal konsepti, fonksiyonel yükleme öncesinde 3-6 aylık bir iyileşme süresine sahip iki-aşamalı cerrahi prosedürü içermektedir (Stephen ve ark. 2007). Buna ek olarak son dönemde, erken yükleme protokolünü teşvik eden ve olumlu sonuçlar ortaya koyduğunu gösteren birçok klinik çalışma yapılmıştır (Popper ve ark. 2003, Engstrand ve ark. 2003, Engstrand ve ark. 2001). Bu protokol sayesinde hastaların kaybolan estetik ve fonksiyonu daha kısa sürelerde geri kazandırıırken, ikinci bir operasyon ve geçici protez yapımı gibi bazı prosedürlerin devre dışı bırakılmasıyla tedavi süreci daha konforlu ve kolay bir şekilde tamamlanabilmektedir (Cannizzaro ve ark. 2007, Turkyilmaz ve ark. 2006, Peñarrocha-Oltra ve ark. 2013). Branemark'ın 1999 yilında ortaya koyduğu Branemark Novum Metodu ve All-on-4 konsepti erken yükleme protokolünü temel alan iki yöntem olarak belirtilebilir. Her iki yöntem için de, özellikle anterior mandibula bölgesinde başarılı sonuçlar elde edildiğini gösteren çalışmalar mevcuttur (Branemark ve ark. 1999, Engstrand ve ark. 2003, Malo ve ark. 2005). Bu konseptlerin yanı sıra, son dönemdeki çalışmalarda olumlu sonuçlar ortaya koyduğu belirlenen OSU protokolü de anterior mandibula bölgesine uygulanan implant destekli hibrit protez yapımını içeren bir erken yükleme yöntemidir. Diğer yöntemlerden farklı olarak protetik tedavi için operasyon sonrası ölçü alım prosedürlerini içermemektedir. Operasyon sonrasındaki ilk 3 ya da 4 . günde protez ağıza yerleştirilir (Tames ve ark. 2004). Bu protokolde, diğer erken yükleme konseptini baz alan 
yöntemlerde olduğu gibi kaliteli bir kemik gerekliliği mevcuttur. Bununla alakalı yapılan çalışmalarda, çoğu hastada iyi bir kemik kalitesine sahip olan anterior mandibula bölgesinin, ağızın diğer bölgelerine nazaran daha başarılı sonuçlar ortaya koyduğu gösterilmiştir (Jemt ve ark. 1989, Wolfinger ve ark. 2003, Eckert ve Wollan 1998). Bu çalışmada da, hastanın ağız içi muayenesi ve sosyoekonomik durumu göz önüne alınarak anterior mandibula bölgesine 5 adet dental implant uygulanması sonrasında OSU erken yükleme protokolüne uygun şekilde dental hibrit protez yapımına karar verilmiştir.

Protetik tedavi seçeneği olarak uygulanmasının ardından fonksiyonel ve psikososyal birçok avantajı beraberinde getiren implant destekli sabit hibrit protezler, kimi durumlarda mekanik problemlere, inflamasyon ile alakalı sorunlara ve hatta konuşma ve diksiyon bozukluklarına sebebiyet verebilmektedir (Real-Osuna ve ark. 2012, Jemt 1991). Jemt (1991), bununla alakalı olarak yapmış olduğu çalışmada protetik restorasyonun konuşmaya olan negatif etkisinin önemli komplikasyonlardan biri olabileceğini belirtmiştir. Protetik tedavi sonrasında implant bölgesi ve protezlerin hijyeni ve bu konudaki motivasyon başarı için kritik önem taşımaktadır. Sabit bir protezin temizliği, doğal diş ya da hareketli bir protezin temizliğinden farklılık göstermektedir. İmplant destekli sabit hibrit protezlerde hijyenin etkin bir biçimde sağlanabilmesi için protezin altyapısı ile mukoza arasındaki mesafenin en az $2 \mathrm{~mm}$ olması gerekmektedir. Daha düşük aralık var olduğunda, hastanın protez temizliği konusunda problem yaşayabileceği belirtilmiştir (Turkyilmaz ve ark. 2009, Kreuter 2008). Erken yükleme konseptinde operasyonun hemen sonrasında protetik işlemlere başlandığından, yapım sırasında protezin uyumu değerlendirilirken komşu yumuşak dokularda iyileşme süresi boyunca meydana gelebilecek değişiklikler göz önünde bulundurulmalıdır. Bengazi ve ark. (1996), yapmış oldukları çalışmada implant operasyonu sonrasında iyileşme sürecinde yumuşak doku çekilmelerinin meydana gelebildiği ve bu çekilmenin büyük bir kısmının operasyon sonrasındaki ilk 6 ayda ortaya çıktığını göstermişlerdir. Bu çalışmada, OSU protokolüne uygun hazırlanan implant destekli hibrit protezin altyapısı ile mukoza arasında hijyen için bırakılan 2mm'lik boşlukta, protezin ağıza yerleştirilmesinin ardından postoperatif iyileşme süresince çevre yumuşak dokularda meydana gelen değişikliklere bağlı olarak artış meydana gelmiştir. Bu durum hastanın fonasyonunda ve diksiyonunda problemlere yol açmıs, psikososyal olarak negatif etkilenmesine sebep olmuştur. Bu olgu sunumunda hastada meydana gelen bu sorunun çözümü için alternatif bir yöntem anlatımaktadır.

Çalışmada sunulan alternatif yöntemin en önemli avantajı, tekrar bir döküm işlemi ve hatta protez yenileme gerektirmeksizin hastaya maddi olarak ve zaman açısından kazanç sağlamasıdır. Bu sayede tek bir randevuda hastanın var olan şikayetleri giderilmiş olup, sonradan açığa çıkan psikososyal dezavantaj konforlu ve kolay bir şekilde ortadan kaldırılmışıı. Hastanın 1 yıl sonraki kontrolünde yapılan intraoral ve radyografik muayenesinde cerrahi ve protetik olarak herhangi bir problemle karşılaşılmazken, sonradan açığa çıkan fonasyon şikayetinin ise 3 . ay sonunda uygulanan alternatif yöntem ile beraber tamamen ortadan kalktığı belirlenmiştir.

\section{SONUÇ}

$\mathrm{Bu}$ olgu sunumda gösterilen alternatif tekniğin, OSU protokolü baz alınarak erken yükleme konsepti ile ağıza yerleştirilen dental implant destekli hibrit protezlerde postoperatif doku iyileşmesine bağlı olarak ortaya çıkabilecek fonasyon problemlerinin çözümünde geçerli bir yöntem olabileceği gösterilmektedir. Bu yöntemle hastanın karşı karşıya kaldığı psikososyal dezavantaj, konforlu ve kısa bir sürede kolaylıkla ortadan kaldırımıştır. 


\section{KAYNAKLAR}

Bengazi F, Wennstrom JL, Lekholm U, 1996. Recession of the soft tissue margin at oral implants. A 2-year longitudinal prospective study. Clin Oral Implants Res, 7 , 303-310.

Branemark PI, Engstrand P, Ohrnell LO, Gröndahl K, Nilsson P, Hagberg K, Darle C, Lekholm U, 1999. Branemark Novum: a new treatment concept for rehabilitation of the edentulous mandible. Preliminary results from a prospective clinical follow-up study. Clin Implant Dent Relat Res, 1, 2-16.

Cannizzaro G, Leone M, Esposito M, 2007. Immediate fuctional loading of implants placed with flapless surgery in the edentulous maxilla: 1-year follow-up of a single cohort study. Int $J$ Oral Maxillofac Implants, 22, 87-95.

Cooper LF, Ellner S, Moriarty J, Felton DA, Paquette D, Molina A, Chaffee N, Asplund P, Smith R, Hostner C, 2007. Three-year evaluation of single-tooth implants restored 3 weeks after 1-stage surgery. Int J Oral Maxillofac Implants, 22, 791-800.

Desmet E, Duyck J, VanderSloten J, Jacobs R, Naert I, 2007. Timing of loading immediate, early, or delayed in the outcome of implants in the edentulous mandible: A prospective clinical trial. Int $\mathrm{J}$ Oral Maxillofac Implants, 22, 580-594.

Eckert SE, Wollan PC, 1998. Retrospective review of 1170 endosseous implants placed in partially edentulous jaws. J Prosthet Dent, 79, 415-421.

Engquist $B$, Astrand $\mathrm{P}$, Anzen $\mathrm{B}$, Dahlgren $\mathrm{S}$, Engquist $E$, Feldmann $H$, Karlsson $U$, Nord PG, Sahlholm S, Svärdström P, 2005. Simplified methods of implant treatment in the edentulous lower jaw: A 3year follow-up report of a controlled prospective study of one-stage versus two-stage surgery and early loading. Clin Implant Dent Relat Res, 7, 95-104.

Engstrand P, Grondahl K, Ohrnell LO, Nilsson P, Nannmark U, Branemark PI, 2003. Prospective follow-up study of 95 patients with edentulous mandibles treated according to the Branemark Novum concept. Clin Implant Dent Relat Res, 5, 310.

Engstrand P, Nannmark U, Martensson L, Galeus I, BranemarkPI, 2001. Branemark Novum: prosthodontic and dental laboratory procedures for fabrication of a fixed prosthesis on the day of surgery. Int J Prosthodont, 14, 303-309.

Friberg B, Henningsson C, Jemt T, 2005. Rehabilitation of edentulous mandibles by means of turned Branemark System implants after one-stage surgery: a 1-year retrospective study of 152 patients. Clin Implant Dent Relat Res, 7, 1-9.
Friberg B, Gröndahl K, Lekholm U, Branemark PI, 2000. Long-term follow-up of severely atrophic edentulous mandibles reconstructed with short Branemark implants. Clin Implant Dent Relat Res, 2, 184-189.

Gracis SE, Nicholls JI, Chalupnik JD, Yuodelis RA, 1991. Shock-absorbing behavior of five restorative materials used on implants. Int J Prosthodont, 4, 282291.

Henry R, Rosenberg I, 1994. Single-stage surgery for rehabilitation of the edentulous mandible: Preliminary results. Pract Periodontics Aesthet Dent, 6, 15-22.

Jemt T, 2008. Single implants in the anterior maxilla after 15 years of follow-up: comparison with central implants in the edentulous maxilla. Int $\mathrm{J}$ Prosthodont, 21, 400-408.

Jemt T, Lekholm U, Adell R, 1989. Osseointegrated implants in the treatment of partially edentulous patients: A preliminary study on 876 consecutively placed fixtures. Int $\mathrm{J}$ Oral Maxillofac Implants, 4, 211217.

Jemt T, 1991. Failures and complications in 391 consecutively inserted fixed prostheses supported by Brånemark implants in edentulous jaws: a study of treatment from the time of prosthesis placement to the first annual checkup. Int J Oral Maxillofac Implants, 6, 270-276.

Kreuter KS, 2008. A retrospective evaluation of immediate load implant-supported definitive hybrid cases performed at the Osu Omfs resident clinic. A Thesis, Ohio State University.

Malo P, Nobre MA, Borges J, Almeida R, 2012. Retrievable Metal Ceramic Implant-Supported Fixed Prostheses with Milled Titanium Frameworks and AllCeramic Crowns: Retrospective Clinical Study with up to 10 Years of Follow-Up. J Prosthodont, 21, 256-264.

Malo P, Rangert B, Nobre M, 2005. All-on-4 immediatefunction concept with Branemark System implants for completely edentulous maxillae: a 1-year retrospective clinical study. Clin Implant Dent Relat Res, 1, 88-94.

Nedir R, Bischof M, Szmukler-Moncler S, Belser UC, Samson J, 2006. Prosthetic complications with dental implants: from an up-to-8-year experience in private practice. Int J Oral Maxillofac Implants, 21, 919-928.

Peñarrocha-Oltra D, Covani U, Aparicio A, Ata-Ali J, Peñarrocha-Diago M, Peñarrocha-Diago M, 2013. Immediate versus conventional loading for the maxilla with implants placed into fresh and healed extraction sites to support a full-arch fixed prosthesis: nonrandomized controlled clinical study. Int J Oral Maxillofac Implants, 28, 116-124 
Popper HA, Popper MJ, Popper JP, 2003. The Branemark Novum protocol: description of the treatment procedure and a clinical pilot study of 11 cases. Int J Periodontics Restorative Dent, 23, 459-465.

Preciado A, Del Rio J, Lynch CD, Castillo-Oyagüe R, 2013. A new, short, specific questionnaire (QoLIP-10) for evaluating the oral health-related quality of life of implant-retained overdenture and hybrid prosthesis wearers. J Dent, 41, 753-763.

Real-Osuna J, Almendros-Marqués N, Gay-Escoda C, 2012. Prevalence of complications after the oral rehabilitation with implant-supported hybrid prostheses. Med Oral Patol Oral CirBucal, 17, 116-21.

Stephan G, Vidot F, Noharet R, Mariani P, 2007. Implant-retained mandibular overdentures: a comparative pilot study of immediate loading versus delayed loading after two years. J Prosthet Dent, 97, 138-145.

Tames R, McGlumphy E, El-Gendy T, Wilson R, 2004. The OSU frame: A novel approach to fabricating immediate load fixed-detachable prostheses. J Oral Maxillofac Surg, 62, 17-21.

Tarnow DP, Emtiaz SS, Classi A, 1997. Immediate loading of threaded implants at stage I surgery in edentulous arches: Ten consecutive case reports with 1 to 5-year data. Int J Oral Maxillofac Implants, 12, 319324.

Turkyilmaz I, Suarez JC, Company AM, McGlumphy EA, 2009. Early load mandibular hybrid prosthesis using the Ohio State University acrylic frame requiring no final impression. Aust Dent J, 54, 255-261.

Turkyilmaz I, Tozum TF, Tumer C, Ozbek EN, 2006. A 2year clinical report of patients treated with two loading protocols for mandibular overdentures: Early versus conventional loading. J Periodontol, 77, 1998-2004.

Wolfinger G, Balshi T, Rangert B, 2003. Immediate functional loading of branemark system implants in edentulous mandibles: Clinical report of the results of developmental and simplified protocols. Int $\mathrm{J}$ Oral Maxillofac Implants, 18, 250-257.

Yazışma Adresi:

Yrd.Doç.Dr. Serdar KILIÇ

Kocaeli Üniversitesi

Diş Hekimliği Fakültesi Protetik Diş Tedavisi AD

Yuvacık Yerleşkesi

41190 Başiskele-Kocaeli-TÜRKIYE

Tel : +905326647508

E-mail: serdarklic@gmail.com 